\title{
Relationship between NCE III Business Education Students Computational Skill and their Cumulative Grade Point Average (CGPA) in Colleges of Education in Bauchi and Gombe States
}

\author{
Chadi, Aishatu Muhammad ${ }^{1}$ \\ 'Department of Vocational and Technology Education, Faculty of Technology Education, Abubakar Tafawa \\ Balewa University Bauchi, Nigeria \\ Email.ummuzakkyol@gmail.com
}

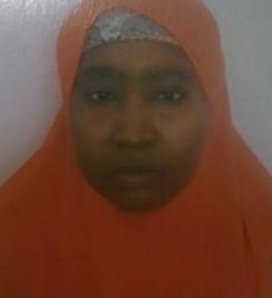

\begin{abstract}
The study aimed at establishing the relationship and prediction power of Business Education students' computational skill (CPS) on their academic performance (CGPA) at college of education level. Two research questions and two hypotheses were formulated for the study. The design of the study was a correlational survey design. The population of the study were 408 NCEIII business education students and stratified random sampling was employed in selecting the research sample. Data collected from a CPS test and analysed using Microsoft Excel (2007). The results of relationship between CPS and CGPA received. 226 which is a low but positive, with a prediction power of $25.57 \%$ showing low relationship but strong predicting paper. It was therefore recommended that Business education departments should strive hard to create students awareness on the relevance of Computational skill to their field of study and to device means of improving students' computational skill for an enhanced performance.
\end{abstract}

Keywords: Business education, Computational skill, Prediction, Relationship, Academic performance.

Citation | Chadi, Aishatu Muhammad (2017). Relationship between NCE III Business Education Students Computational Skill and their Cumulative Grade Point Average (CGPA) in Colleges of Education Cuchi and Gombe States. Journal of Education and e-Learnin in Bauchi and Gombe Research, 4(3): 118-191.

History:

Received: 17 April 2017

Revised: 30 October 2017

Accepted: 3 November 2017

Published: 7 November 2017

Licensed: This work is licensed under a Creative Commons

Attribution 3.0 License (cc) E

Publisher:Asian Online Journal Publishing Group
Funding: This study received no specific financial support.

Competing Interests: The author declares that there are no conflicts of interests regarding the publication of this paper.

Transparency: The author confirms that the manuscript is an honest, accurate, and transparent account of the study was reported; that no vital features of the study have been omitted; and that any discrepancies from the features of the study have been omitted
study as planned have been explained.

Ethical: This study follows all ethical practices during writing.

\section{Contents}

1. Introduction

2. Methodology

119

3. Results and Discussion 


\section{Introduction}

The discipline of business education is without any doubt concerned with proficiency and accuracy numerical measurement. Most business educators believed that the skills is important for students to understand issues pertaining accounting system and financial analysis. Yunker et al. (2009) have the opinion that academic and professional success in business will be facilitated by a high level of mathematical skills. However, the importance of computational skills can be seen in business education courses such as economics, business mathematics, quantitative techniques, accounting and business finance. Competency in the skill make possible students to solve simultaneous equations, understand the concept of a functional relationship, and that of common functions in modelling business concepts, use abstraction to build simple model. Computational skill also support business education students to apply basic concept to business problems, calculation of rates of change, measures of central tendency and that of dispersion, probability, discrete and continuous probability distribution and hypothesis testing. It also make possible for them to examine, summarise, analyse graph and interpret data sets used in business. The Philosophy and objectives of NCE Business Education emphasised the provision of intellectual and professional background adequate for teaching business subjects and posses the right skill that will enable them to engage in the life of work. Eiselen et al. (2004) concluded that computational skill assist business education students to develop arithmetical operations and use of numerical information, translate problem situation into their symbolic representations and use those representations to solve problems. Ballard and Johnson (2004) explained that Problem areas in business mathematics are algebra, calculus, statistics and probabilities that deficiency in those aspects made business students to perform poorly in business courses.

Lack of strong mathematical skills in a number of students who are enrolled in business education courses is one of the more significant challenges facing instructors of business education Gallo and Johnson (2008) explained that; students who struggle with basic math skills tend to perform poorly; because understanding many of the business economics models being taught assumes at a minimum, this was proved in their study of business education students. The result indicated that students who took advanced math courses perform significantly better, while the effect was negative for students who do not take advance math in their previous study.

\subsection{Statement of the Problem}

Despite the predominance of opinion on the effect of computational skills on business education students' achievement, there are little or no literature on the extent of relationship between computational skill and academic performance of Nigerian Certificate in Education (NCE) Business Education in Nigeria . The prediction power of computational skill on NCE students' academic success is also in search and not available to the researchers best knowledge. However, the work seeks to address issues around the extent of relationship and prediction power of computational skill on business education students' academic performance in Nigerian colleges of education.

\subsection{Research Questions}

i What is the relationship between NCE III Business Education Students' computational skill that (CPS) results and their Cumulative Grade Point Average (CGPA)?

ii To what extent can scores in computational skill test (CPS) predicts Cumulative Grade Point Average (CGPA) of NCE III Business Education Students?

\subsection{Research Hypotheses}

The following null hypotheses guided the study:

$\mathrm{H}_{01}$ There is no significant relationship between NCE III Business Education Students' computational skill test (CPS) and their Cumulative Grade Point Average (CGPA).

$\mathrm{H}_{02} \quad$ NCE III Business Education Students computational skill test is not a significant factor that predicts their Cumulative Grade Point Average (CGPA).

\section{Methodology}

The design for the study was correlation survey design, conducted in Bauchi and Gombe states. Both the two states were located in the North-East sub-region of Nigeria. Population of the study were 408 NCEIII Business Education students; from College of Education (COE) Azare, Bauchi state and Federal College of Education (FCET) Gombe, Gombe state. Specifically, 329 NCEIII students were from School of Business studies, Federal College of Education Technical Gombe, Gombe state, and the 79 NCE III students from Business Education Department of Vocational and Technical Education Programme, College of Education Azare, Bauchi state. Random sampling was finally used in the selection of the required number of students from each institution. The study sampled 155 students, 120 from FCET Gombe and 35 from COE Azare using stratified proportional random sampling.

Table-1. Population and Selected Sample for the Study.

\begin{tabular}{|c|c|c|c|c|c|}
\hline $\mathbf{S} / \mathbf{N}$ & Institution & Location & Level & Population & Sample \\
\hline 1 & $\mathrm{FCE}(\mathrm{T})$ & Gombe & NCE111 & 329 & 120 \\
\hline 2 & $\mathrm{COE}$ & Azare & NCE 111 & 79 & 35 \\
\hline Total & & & & 408 & 155 \\
\hline
\end{tabular}

Education Colleges of Education Bauchi and Gombe States

Two research instruments were used to collect data from the subjects for the study. These were: Computational Skill Test (CPS), Students (subjects) Cumulative Grade Point Average (CGPA).

Computational skills test (CPS) was an adopted standardized questions selected from Nigerian Certificate in Education NCE (STUP, 2007) general studies education course book I and II. It has two sections, A and B. Section A consisted of the bio-data of the respondents, and section B a classroom test of computational skill consisted of a 
twenty five item multiple choice test with option a-d. The content of the CPS covers number bases and indices, percentages, simple interest, ratio and proportions, linear equation, graph, statistics, calculus. Students were expected to tick or circle the correct options.

Data for the study was collected by administering the computational skill test (CPS) on the sampled students by the researcher with the help of research assistants (two people from ATBU Bauchi and two people from the selected colleges respectively) The test instrument was administered to the sample students during their normal periods in their respective schools. The data collected was analyzed using Microsoft Excel 2007. Pearson correlations, standard deviation, mean and prediction were calculated at 0.05 level of significance; to determining the relationships and prediction between the variables in the research question and the research hypothesis.

\section{Results and Discussion}

Computational skill that (CPS) was the instruments used for data collection. The result from the tests was compared against the students' cumulative grade point average (CGPA) obtained from their respective departments. Analysis was made using Microsoft excel 2007. Presentation follows the order of the research question and hypothesis.

\section{Research Question One}

What is the relationship between NCEII Business Education Students' Computational Skills (CPS) test results and their Cumulative Grade Point Average (CGPA)?

To answer research question one NCEIII Business Education Students Computational Skills Test result was correlated with their CGPA as Presented in Table 2.

Table 2 shows Pearson's correlation test results of NCE III business education students with $\mathrm{N}=155$, degree of freedom is 153 , mean of 2.55 for CGPA and 37.200 for CPS, standard deviation of 16.7575 for CGPA and 14.755 for CPS, R-value is .226. This shows that relationship is not significant between Business Education Students' CPS and their CGPA.

Null Hypothesis One: There is no significant relationship between NCEIII business education students' computational skills and their cumulative grade point average (CGPA).

To test for hypothesis one, NCE III business education students' Computational Skills test results was correlated with their CGPA as presented in Table 2.

Table 2 shows a mean of 2.55 for CGPA and 37.200 for CPS. R-value of 0.226 at 0.05 level of significance. The null hypothesis was accepted because the result revealed no significant relationship between business education students' CPS and their CGPA.

Table-2. Mean, standard deviation and R value of NCEIII Business Education Students' CPS and their CGPA.

\begin{tabular}{l|c|c|l|l|l|l}
\hline Variables & N & df & mean & sd & r & Decision \\
\hline CGPA & 155 & 153 & 2.55 & 16.958 & & \\
\hline & 155 & & 37.200 & 14.755 & & \\
\hline CPS and CGPA & & & & & .226 & Not significant \\
\hline at 0.05 level of significance & & & &
\end{tabular}

at 0.05 level of significance

\section{Research Question Two}

To what extent can scores in computational skill test (CPS) predicts Cumulative Grade Point Average (CGPA) of business education students?

To answer research question two, prediction is used to determine the extent that Business Education Students' CGPA can be predicted from their Computational Skill test.

Table 3 shows the prediction of NCE III Business Education Students' CGPA from their CPS. The results indicates a mean of 2.55 for CGPA and 37.200 for CPS, standard deviation of 16.757 for CGPA and 14.755 for CPS predicted by $25.57 \%$, at 0.05 level of significance. The results revealed $25.57 \%$ of Business Education Students' CGPA will come from their computational skill.

Null Hypothesis Two: NCE III Business Education Students' computational skill is not a significant factor in predicting their Cumulative Grade Point Average (CGPA).

To test for hypothesis two, prediction is used to predict NCE III Business Education Students' CGPA from their CMS.

Table 3 shows mean of 2.55 for CGPA and 51.618 for CPS, standard deviation of 16.757 for CGPA and 14.755 for CPS, predicting by $25.57 \%$ at 0.05 level of significance. The null hypothesis is rejected because CPS is significant in predicting business Education students' CGPA.

Table-3. Mean, standard deviation \& prediction of NCE III Business Education Students' CGPA from their CPS

\begin{tabular}{l|l|l|l|l|l|l}
\hline Variables & N & Df & Mean & SD & Prediction & Decision \\
\hline CGPA & 155 & 153 & 2.55 & 16.757 & & \\
\hline CPS & 155 & & 37.200 & 14.755 & & \\
\hline CGPA and CPS & & & & & $25.57 \%$ & Significant \\
\hline at 0.05 level of significant & & & &
\end{tabular}

\subsection{Summary of the Findings}

1 There is a low positive Relationship of. 226 between NCE III Business Education Students' Computational Skill and their academic performance.

2 NCE III Business Education Students' academic performance can be predicted from their computational skill by $25.57 \%$.

3 Hypothesis testing indicates no significant relationship between NCE III Business Education Students' Computational Skills and their academic performance. 
4. NCE III Business Education Students' Computational Skills is a significant factor in predicting their academic performance.

\subsection{Discussions of the Findings}

The findings revealed that Computational skill had no significant relationship with Business Education Students' academic performance. This shows a disparity with the findings of Gallo and Johnson (2008) who reported that many students with greater math skill performed better on the applied portion of the mathematical aspect of business education courses.

The finding also revealed that Business Education Students' CGPA can be predicted by Computational skill. The finding of Yunker et al. (2009) supported the current finding that math ability has statistical incremental power over CGPA. The same group conducts another study in (2009) and the study of Ballard and Johnson (2004) both reported their findings that math ability has positive effect on business education students' performance.

\subsection{Summary}

The study determined the relationship between Computational Skills of Business Education Students' and their academic performance in Bauchi and Gombe states. Importance of computational skills to academic performance of Business Education Students' was captured; as competency and proficiency in the skill help students to develop strategies and technique for identifying and solving problems. Two research objectives, two research questions and two hypotheses were formulated for the study. The design of the study was correlation survey design, with Gombe and Bauchi states as the areas of study. The population of the study was 408 NCE11 1 Business Education Students from College of Education Azare and Federal College of Education Gombe (2011-2012) academic session. Random sampling technique was used for the selection of the sample. A total of 155 students were selected for the study. 35 NCEIII students from College of Education Azare and 120 from Federal College of Education Gombe were involved for the study. The instrument for data collection was 25 items computational skills test (CPS) an adopted standardized questions selected from Nigerian Certificate in Education NCE (2007) general studies education course book I and II). Face and content validity were obtained for the instrument from three experts one from vocational and technology education programme of ATBU and one each from COE Azare and FCE Gombe respectively. COE Jalingo, Taraba state was used for pilot testing. Difficulty level, discrimination index, and reliability coefficient were obtained in the pilot testing. Acceptable range for the item selection was 0.25-0.75. Values that do not fall within that range were rejected. The reliability coefficient obtained was 0.60 . Twenty five (25) items were selected out of thirty five (35) items. The instrument was administered by the researcher with the help of research assistants. Data were analyzed using Microsoft Excel 2007. The results revealed a mean of 2.55 for CGPA and 37.200 for CPS. Also a relationship of. 226 between CPS and CGPA was obtained with predicting power of $25.57 \%$.

\subsection{Recommendations}

The following are the recommendations of the study:

1-Business education schools and programs should strive to improve their students' academic performance through effective development of communication and computational skills.

2-Teachers should develop strategies for enhancing communication and computational skills among their students. 3-Students should be enlightened on the relevance of communication and computational skills to their academic performance.

\subsection{Conclusion}

Based on the findings and discussions of the study, NCE III Business Education students' overall results was at the average and moved together with their computational skill. Their overall performance and their Computational were all not appreciative. The relationship was positive but low this implies that they are weak in Computational skill. Their weakness in Computational skill was among the factors that made the overall results weak. However, it was significant in predicting their academic performance. Therefore improvement in Computational skill can lead to improvement of their academic performance.

\section{References}

Ballard, C.L. and M.F. Johnson, 2004. Basic math skills and performance in an introductory economics class. Journal of Economics Education, 35(2): 3-23. View at Google Scholar | View at Publisher

Eiselen, S., F. Strauluss and L. Jouck, 2004. The basic mathematical skills test as a predictor of performance in mathematics in tertiary level. Journal of Mathematics, 5(78): 23-30.

Gallo, A.A. and K.J. Johnson, 2008. Math skills and everyday problem solving. Journal of Economics Education, 1(7): 7-20. View at Google Scholar

Nigerian Certificate in Education NCE, 2007. General stydies book 1\&ll. Federal ministry of Education Nigeria.

Yunker, P.J., J.A. Yunker and G.W. Krull, 2009. The influence of mathematics ability on accounting students' performance in principles of accounting. Accounting Educators Journal, 19: 1-20. 